\title{
Perception of peer drinking and access to alcohol mediate the effect of residence status on alcohol consumption
}

\author{
Katrina A. Williams*a, Nathaniel S. Thomas ${ }^{b, c}$, Amy E. Adkins ${ }^{b, c}$, \& Danielle M. Dick b,c,d \\ a Department of Kinesiology and Health Sciences, Virginia Commonwealth University, Richmond, VA, United States \\ ${ }^{b}$ College Behavioral and Emotional Health Institute, Virginia Commonwealth University, Richmond, VA, United States \\ 'Department of Psychology, Virginia Commonwealth University, Richmond, VA, United States \\ ${ }^{d}$ Department of Human and Molecular Genetics, Virginia Commonwealth University, Richmond, VA, United States
}

Student:williamska5@vcu.edu*

Mentor: thomasns@vcu.edu

\begin{abstract}
Alcohol consumption is common in college attending populations and can have a negative impact on an individual's academic, physical, and mental health. Previous research suggests that living at home could act as a protective measure. The current research looks at potential mediators of the association between living with parents while attending college and amount of alcohol consumed. In particular, this study examined access to alcohol, parental involvement, and perception of peer drinking as mediators of the association. This study examined freshman data collected from a survey conducted at a large public university in the mid-Atlantic United States. A pathway model was fit to test the relationships between residence status, access to alcohol, parental involvement, and perception of peer drinking on alcohol consumption. We observed statistically significant indirect effects of residence status on alcohol consumption through the perception of peer drinking and access to alcohol. Parental involvement was significantly related to lower alcohol consumption and there was a direct effect of residence status on alcohol consumption. There were significant indirect effects of residence status on alcohol consumption through both peer drinking and access to alcohol. Parental involvement was associated with decreased alcohol consumption, with no indirect effect in association with residence status. These effects were persistent in the presence of a range of covariates, including age, gender, ethnicity, and parental education.
\end{abstract}

KEYWORDS: Emerging Adult; Alcohol; Residence Status; Peer Drinking; Access to Alcohol; Parental involvement; Path Analysis

\section{INTRODUCTION}

According to the Centers for Disease Control (CDC), the use of alcohol and illegal substances represent a considerable burden to public health. ${ }^{1}$ Data published through the CDC indicate that in 2006 excessive drinking equated to an average of $\$ 746$ of public health spending per person per year and is associated with upwards of 50 or more distinct injuries and diseases, such as car accidents, sexually transmitted diseases, and alcohol dependence. ${ }^{1}$ Prevalence estimates from the past decade suggest that roughly $40 \%$ of college students endorse episodic heavy drinking in the past month. ${ }^{2,3}$ Relatedly, $18 \%$ of college students report experiencing clinically-significant problems with alcohol use. ${ }^{4}$

The consequences associated with heavy alcohol use in college-attending, emerging adult populations are stark. Excessive alcohol use is associated with lower GPA, ${ }^{5,6}$ discontinuous enrolments in third- and fourth-year students, ${ }^{7}$ and select neurocognitive deficits. ${ }^{8}$ Emerging adulthood also often represents a critical period in psychosocial and behavioral development, where relatively persistent trajectories in behavior and pathology are likely to begin. ${ }^{9}$ Thus, excessive alcohol use in emerging adult college students may represent both an acute threat to academic performance, as well as a risk factor for problems with alcohol later in development.

Multiple reasons have been posited for why college attendance is associated with increased alcohol use. The increase in alcohol consumption in college-attending populations is often attributed to an increase in independence and relative lack of adult responsibilities such as full-time employment and child-rearing; although the Transition Catalyst Model suggests that this increase in alcohol consumption is due to a desire to acclimate to the new situations and circumstances that colleges students find themselves in. ${ }^{10,11}$ As college students enter into an environment associated with higher alcohol consumption, they may drink more in the process of acclimation. Despite the fact that many college students consume more alcohol during their time in college, there is a small portion of individuals that do not follow this particular trend. Individuals who live at home during their 
college-attending years have a lower prevalence of risky patterns alcohol use, such as binge drinking and blacking out. These individuals also report overall lower alcohol consumption than their college-attending peers who live on campus. ${ }^{12}$

When examining college-attending populations, many studies define living at home as a controlled environment, or a living circumstance that minimizes risk factors for hazardous behavior. Operationally, Wechsler, et al. (2002) defines a controlled living environment as a substance-free residence hall or off-campus with parents; statistics on this population are often not exclusive to those living at home, but rather all college students who live in a controlled environment. ${ }^{13}$ It is feasible that this operationalization of a controlled living environment homogenizes important variation within this broader group, failing to measure contextual nuance unique to living with one's parents. In the current analyses, we focus specifically on those individuals living with their parents.

Previous research suggests that living with parents could decrease a college student's risk of consuming excessive amounts of alcohol. ${ }^{12}$ The increased parental influence was seen as a possible protective measure that reduced the amount of alcohol that a college student would drink. ${ }^{14}$ Another study conducted by Baer, et al. (1991) found that those under the legal drinking age were less likely to drink if they knew that they would receive negative consequences from their parents (such as a lecture or punishment). ${ }^{15}$ Most of the individuals involved in the study consumed less alcohol so that they would not receive the negative consequences from their parents, suggesting that this residence status may represent a protective factor from excessive alcohol use.

Additional research provides evidence of other factors that may contribute to this relationship, including perceptions of peer drinking, access to alcohol, and parental involvement. Many college students' perception of how much their peers drink is incorrect. ${ }^{15}$ Many have a misconstrued perception of how much their peers drink, which then impacts how they view drinking more generally; individuals who believe that their peers consume excessive amounts of alcohol are more likely to adhere to these perceived social norms and consume excessive amounts of alcohol as well. ${ }^{16}$ Living with one's parents may buffer college students from this misperception, as individuals may spend less time in social situations where alcohol consumption is considered normative, and establish social groups with individuals that their parents would approve of. ${ }^{17}$ This often means that the individuals with fewer maladaptive social connections exhibit fewer risky alcohol use behaviors. ${ }^{18}$ Generally, socializing with others that do not consume alcohol excessively encourages different perceptions of peer drinking, which may dispose these individuals to drink less.

Variation in the extent of college students' access to alcohol may further distinguish students living at home from students living on campus. For those who are under the legal drinking age-21 in the United States_obtaining alcohol requires access to some form of an illicit channel. By utilizing a variety of methods, such as using fake IDs or finding bars that do not check IDs, to obtain alcohol, half of college students under the legal drinking age report that alcohol is very easy to obtain, despite legal restrictions. ${ }^{12}$ For a college student living at home, it may be harder to utilize these methods to obtain alcohol. They may be dissuaded from maintaining a fake ID for fear a parent could find it. They may not have access to stores or bars/clubs that do not card due to living off campus away from locations with a higher density of venues to purchase alcohol. ${ }^{19}$ Furthermore, they may not know an of-age individual who is willing to purchase alcohol for them. All of these would reduce the accessibility of alcohol for this population, making it less likely that they would struggle with the same risky behaviors from which college students living on campus may engage in.

The protective effects of parental involvement are also well-supported in the literature. Low parental involvement is associated with both the initiation of alcohol use and transition to heavy drinking in adolescence. ${ }^{20,21}$ Arria et al. (2008) report that level of high school drinking mediates the relationship between parental involvement in adolescence and college drinking, while other findings indicate the parental involvement in high school exerts a direct influence on college drinking. ${ }^{22,23}$ These findings suggest that early parental involvement may continue to influence behavior into college by setting a precedent for one's drinking early on. Notably, few studies have examined the relationship between continuing to living with one's parents into college and high school parental involvement.

Previous research has shown that college students who live with their parents have a lower rate of alcohol consumption. It has also been seen that parental involvement has a significant role in the decreased alcohol consumption seen in that population. This study will test multiple mediators through a pathway model to determine if perceptions of peer drinking and access to alcohol have an effect on how much alcohol a college student living at home consumes. We hypothesize that 1) perceptions of peer drinking and 2) report of student's ease of access to alcohol will mediate the relationship between living with one's parents and grams of ethanol consumed per month, after accounting for the effect of parental involvement. 


\section{METHODS AND PROCEDURES}

Data Source

The current analyses use data from The Spit for Science project, a longitudinal survey of undergraduate college students from a single university which assesses various aspects of behavioral and emotional health. ${ }^{24}$ The project was launched in 2011 and, at this point, includes four cohorts of undergraduate students. Initial self-report data were collected in the fall semester of incoming freshmen's first year, with follow up assessments at every subsequent spring semester. This procedure was applied to each incoming cohort. Self-report data were collected using an electronic survey programmed in the Research Electronic Data Capture (REDcap) software. Participants are offered \$10 to complete the electronic survey. The Spit for Science sample is generally representative of the demographic characteristics of the university's undergraduate population in terms of sex and race/ethnicity. ${ }^{24}$ Further details, including full explication of the theoretical underpinnings of the broader project, recruitment activities utilized to increase enrollment, and a discussion of selected measures can be found in Dick et al. (2014). ${ }^{24}$ This study was approved by the university's Institutional Review Board. Participants were presented with consent documentation and indicated that they understood the potential risks and benefits of participating.

\section{Measures}

Covariates

Demographic information included age, gender, race/ethnicity, and highest education achieved by each of subjects' parents.

\section{Residence}

Subjects' residence was assessed with a single item in the Fall semester of subjects' first year in college which read "Where do you live while attending university?", with response options "Residence Hall", "Off-campus housing", "Parent's house", and "Other". This measure was then used to calculate an indicator for endorsement of the "Parent's house" category, to be compared with subjects endorsing any of the other categories.

\section{Steinberg Parenting Style, Parental Involvement}

Parental involvement was assessed in the Fall semester of subjects' first year in college using the Involvement subscale of the Steinberg Parental Style inventory. ${ }^{25}$ This subscale is comprised of three items. The first item read, "My parents helped me with schoolwork if there was something I didn't understand." The second item read, "My parents knew who my friends were". The third item read, "My parents spent time just talking with me". Response options for these three items were (1) "Strongly Agree", (2) "Agree somewhat", (3) "Disagree somewhat", (4) "Strongly Disagree". Scores on these items were summed after being reverse coded, such that a higher sum score would reflect greater parental involvement $(\alpha=0.68)$. Missing data were pro-rated if a given subject had answered at least two of the three items. The resulting sum score had a minimum value of three and a maximum value of 12.

\section{Peer Drinking}

Peer drinking was assessed in the Spring semester of subjects' first year in college with a single item which read "The following question are about your friends - friends you would have seen regularly and spent time with in school or outside of school. Please answer for your friends that you spend time with since starting school. How many of your friends have done the following? How many would have drunk alcohol?" with response options (1) "None", (2) "A few", (3) "Some", (4) "Most" and (5) "All".

\section{Access to Alcohol}

Access to alcohol was assessed with a single item in the Spring semester of subjects' first year in college which read, "How easy is it for you to obtain alcohol currently?", with response options (1) "Very difficult", (2) "Difficult", (3) "Easy" and (4) "Very easy".

\section{Grams of ethanol consumed per month}

Grams of ethanol consumed per month was calculated from separate measures of quantity and frequency of alcohol consumption in the Spring semester of subjects' first year in college. Frequency of alcohol consumption was measured with one categorical item, "How often do you have a drink containing alcohol?", with response options "Never", "Monthly or less", "2 to 4 times a month", "2 to 3 times a week", and "4 or more times a week". Quantity of alcohol consumption was measured with one categorical item, "How many drinks containing alcohol do you have on a typical day when you are drinking?", with response options "1 or 2 ", " 3 or 4 ", "5 or 6", "7, 8, or 9", and "10 or more". 
Together, these ranges were converted to a measure of grams of ethanol consumed per month using a procedure described in previous literature. ${ }^{26,27}$ Frequency categories were converted to the median of the range of each response option to reflect drinking occasions per month, i.e. "Never" $=0$, "Monthly or less" $=0.5$, "2-4 times a month" $=3$, "2-3 times a week" = 10.7. The "4 or more times a week" category was set equal to 23.54 , based on the average count of 4.28 weeks per month, for a possible range of 17.12- 29.96 drinking days per month Drinking quantity was quantified using a similar procedure, i.e. "1 or 2 " $=1.5$, “3 or 4" = 3.5, " 5 or $6 "=5.5, " 7,8$, or $9 "=8$. The " 10 or more" category was set equal to 15 based on the specification of 21 as the upper limit of drinks per occasion, in alignment with a similar continuous measure in the Spit for Science survey.

The product of recoded frequency and quantity was then multiplied by 14, which represents the grams of ethanol contained in a single, standard drink in the United States. These calculations were applied to each individual's data on quantity and frequency. The resulting measure is a pseudo-continuous measure of alcohol consumption that may adopt 25 different values. Grams of ethanol consumed per month was transformed by the natural log, plus a constant of 1 to retain individuals who reported no past month alcohol use to limit distributional problems associated with outliers in this measure.

Data Analysis

A path analysis was conducted to test mediational hypotheses in $\mathrm{R}$ using the "lavaan" package. Estimation by maximum likelihood allowed the use of the full sample $(n=9,889)$. All regressions in the model controlled for mother's education, father's education, age, gender, and ethnicity.

Indirect effects were calculated in "lavaan" as the product of corresponding path coefficients. All reported coefficients were standardized to facilitate clear interpretation.

\section{RESULTS}

\section{Sample Composition}

The sample used in the current analyses was drawn from 4 cohorts of longitudinal data collected between the years 2011-2014 at a public university in the Mid-Atlantic region of the United States (total $n=9,889$ ). Maximum likelihood estimation permits the use of subjects with incomplete data and sample size varies to some extent between measures; a complete description of the sample can be found in Table 1. All measurements were drawn in the Fall or Spring of students' first year of college.

\section{Path model}

Multiple fit indices suggest that the specified model fit our data exceptionally well (Chi-square P-value $=0.246$; RMSEA=0.006, 90\% CI: (0, 0.022); CFI= 1.00).

Effect sizes were standardized for interpretability. Broadly, the hypotheses laid out in the current manuscript were supported. We observed a statistically significant indirect effect of residence status on alcohol consumption through the perception of peer drinking (beta $=-0.494, \mathrm{P}=<0.001$ ), to suggest that living with one's parents reduces perceptions of perceived peer drinking on alcohol use. Similarly, we observed a statistically significant indirect effect of residence status on alcohol consumption through access to alcohol (beta $=-0.102, \mathrm{P}<0.01$ ), to suggest that living with one's parents may limit access to alcohol and — subsequentlyreduce alcohol use. No indirect effect through parental involvement was observed, although parental involvement itself was significantly related to lower alcohol consumption (beta $=-0.031, \mathrm{P}<0.01$ ). These relationships did not fully explain the relationship between residence status and alcohol consumption; we also observed a direct effect of residence status on alcohol consumption (beta $=-0.617, \mathrm{P}=<0.001)$. Complete explication of model coefficients can be found in Figure 1.

\section{Sensitivity Analyses}

An additional iteration of the path model with covariates removed was run to assess the effect of included demographic covariates on results. Results from this model suggest that the patterns of association we have observed are generally robust. The path model without covariates replicated previously observed indirect effects of residence status on alcohol use through the perception of peer drinking (beta $=-0.636, \mathrm{p}<0.001$ ) and access to alcohol (beta $=-0.172, \mathrm{P}=0.002$ ). Again, there was no indirect effect associated with involved parenting style and the direct effect of involved parenting style to alcohol consumption did not reach statistical significance (beta=-.024, $\mathrm{P}=0.06$ ). A direct effect of residence on alcohol use remained $(\mathrm{beta}=-0.609, \mathrm{P}<0.001)$. 


\begin{tabular}{|l|l|l|l|l|l|}
\hline \multicolumn{2}{|l|}{ Measure } & Total Sample & \multicolumn{2}{l|}{$\begin{array}{l}\text { Living with } \\
\text { parents }\end{array}$} & \multicolumn{2}{l|}{ Living elsewhere } \\
\hline Gender* & Total n & & \multicolumn{2}{l|}{} \\
\hline & Male & 9820 & 7832 & $2768(35.3 \%)$ \\
\hline & Female & $3780(38.5 \%)$ & $184(2.3 \%)$ & $4595(58.7 \%)$ \\
\hline & & $6040(61.5 \%)$ & $285(3.6 \%)$ & \\
\hline & Total n & & & 7741 & $1145(14.8 \%)$ \\
\hline & White & 9750 & $4881(50.1 \%)$ & $255(3.3 \%)$ & $1395(18.0 \%)$ \\
\hline & Asian & $1615(16.6 \%)$ & $111(1.4 \%)$ & $455(5.9 \%)$ \\
\hline & Black/African American & $1873(19.2 \%)$ & $55(0.7 \%)$ & $534(6.9 \%)$ \\
\hline & Hispanic/Latino & $594(6.1 \%)$ & $22(0.2 \%)$ & $24(0.3 \%)$ & \\
\hline & Other Ethnicity & $787(8.1 \%)$ & & \\
\hline & & & 7865 & & \\
\hline
\end{tabular}

Table 1. Frequencies for measures used in the analysis. Covariates marked with an asterisk

\begin{tabular}{|l|l|l|l|l|}
\hline \multicolumn{2}{|l|}{ Measure } & $\mathbf{n}$ & Mean & SD \\
\hline Involved Parenting Style & Total & & & \\
\hline & Living with Parents & 366 & 9.5 & 2.14 \\
\hline & Living Elsewhere & 5559 & 9.59 & 2.09 \\
\hline Peer Drinking & Total & & & \\
\hline & Living with Parents & 319 & 2.56 & 1.21 \\
\hline & Living Elsewhere & 5165 & 3.19 & 1.19 \\
\hline \multicolumn{2}{|l|}{} & & & 3.19 \\
\hline Access to Alcohol & Total & 4121 & 3.12 & 0.76 \\
\hline & Living with Parents & 194 & 2.96 & 0.84 \\
\hline & Living Elsewhere & 3890 & 3.13 & 0.76 \\
\hline & & & & \\
\hline Grams of ethanol consumed per month & Total & 6016 & $265.3(19)$ & $525.3(38)$ \\
\hline & Living with Parents & 319 & $101.7(7)$ & $275.62(20)$ \\
\hline & Living Elsewhere & 4242 & $260.6(19)$ & $510.92(36)$ \\
\hline
\end{tabular}

Table 2. Descriptive statistics. Descriptive statistics for grams of ethanol (approx. drinks) 


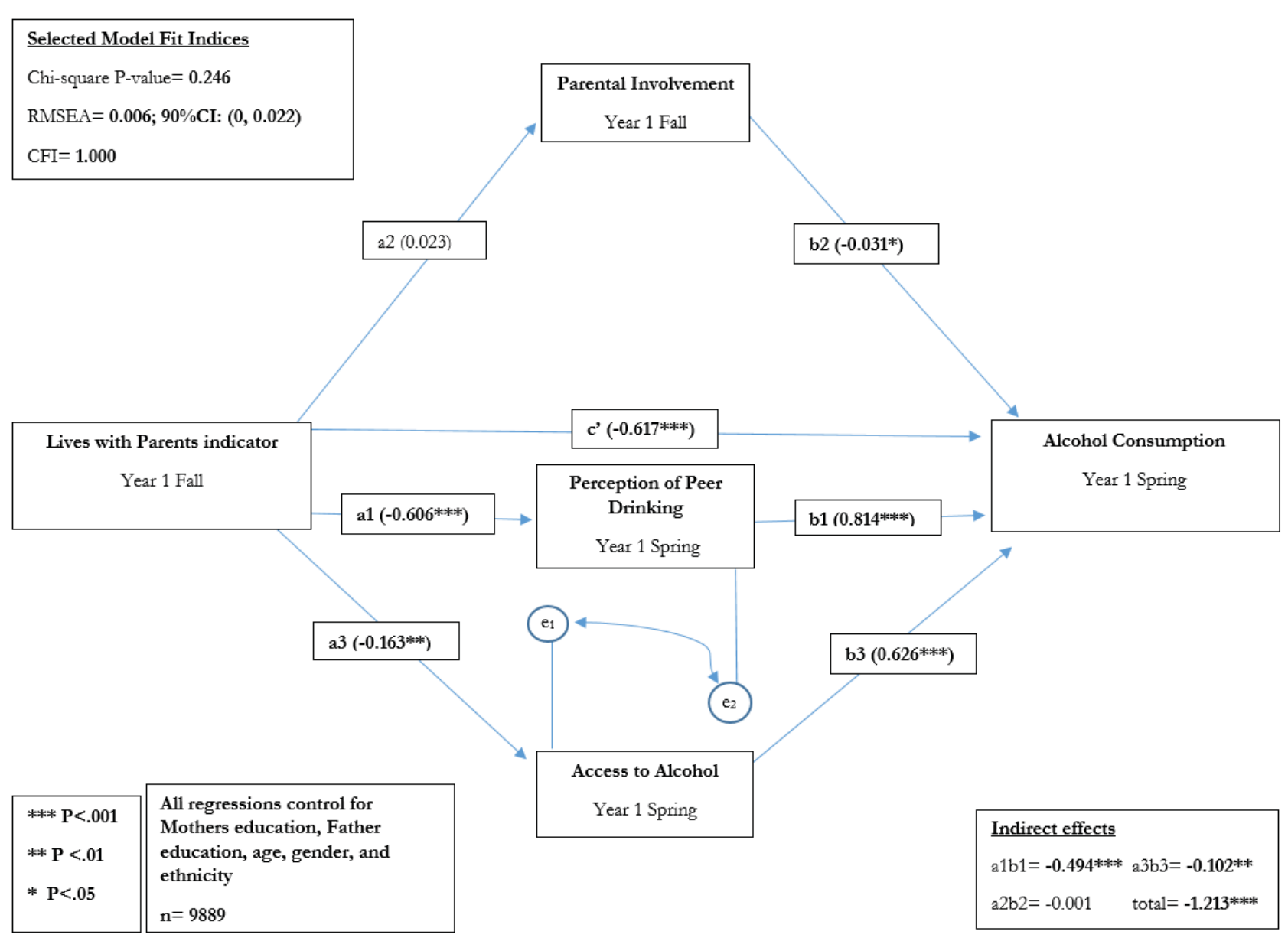

Figure 1. Path model. Perception of Peer Drinking mediates the relationship between living with one's parents and Alcohol Consumption (a1b1 path). Similarly, Access to Alcohol mediates the relationship between living with one's parents and Alcohol Consumption (a3b3 path). Parental involvement does not mediate the relationship between living with one's parents and Alcohol Consumption (a2b2 path). After accounting for these relationships, a direct effect of living with one's parents on Alcohol Consumption remains (c' path).

\section{DISCUSSION}

\section{Key Findings}

In general, the hypotheses laid out in the current manuscript were well supported in our analyses. We hypothesized that 1) perceptions of peer drinking and 2) report of student's ease of access to alcohol would mediate the relationship between living with one's parents and grams of ethanol consumed per month. We observed significant indirect effects of residence status, through both peer drinking and access to alcohol, on alcohol consumption. Parental involvement was associated with decreased alcohol consumption. These effects were persistent in the presence of a range of covariates, including age, gender, ethnicity, and parental education.

The protective effects of living with parents were partially explained by these two mediators. Living with one's parents had an indirect effect on alcohol consumption through the perception of peer drinking and access to alcohol. Living with one's parents was associated with lower perceptions of peer drinking, suggesting that parents play an important role in deciding with whom an individual spends time. Through this mediated association, living with one's parents affects perceived peer drinking. In the same way, living with one's parents affects access to alcohol, which is also associated with lower consumption of alcohol.

\section{Practical Applications}

In some capacity, the benefits of living with one's parents-reduced alcohol use because of lower perceptions of peer alcohol use and less access to alcohol—may be extended to students living on campus by influencing their social environments. Social norms campaigns that reduce the perception of peer alcohol use may subsequently reduce alcohol use in students. It is possible that social norms campaigns can reduce alcohol consumption in the college attending population by changing the way that college 
students, freshmen in particular, view alcohol and their peer's consumption of alcohol. Current research suggests that social norm campaigns may not be as effective as once thought, although other findings suggest that social norm campaigns are more effective on campuses with a lower density of alcohol sales venues around campus. ${ }^{28,29}$ In cases where alcohol sales venue density is higher, or unknown, it may be more effective to use other programs focused on preventing risky alcohol behavior, such as the Brief Alcohol Screening Intervention for College Students (BASICS). ${ }^{30}$ Another way that universities can reduce alcohol consumption through policy change is by implementing more substance-free housing-and strictly enforcing the standards in these residence halls. While some universities already have these options, the substance-free policies are not always consistently enforced, leading to greater access to alcohol. Our results suggested that limited access to alcohol is one benefit of livings with one's parents while attending college; it may stand to reason that university residence halls can emulate this protective effect by placing stricter controls on students' alcohol use.

\section{Limitations}

We observed partial mediation in the current analyses, rather than fully accounting for the effect of residence status on alcohol consumption through indirect effects. There are two possible explanations for the partial mediation. It is possible that residence status in-and-of-itself has a direct effect on alcohol consumption. Otherwise, it is possible that there are additional mediating variables that facilitate the apparent effect of residence status on alcohol consumption. It may be more likely that the second possibility is the cause of the partial mediation, as there are many factors that contribute to alcohol consumption. Future analyses should aim to test other candidate measures to determine what other factors mediate alcohol consumption in college-attending populations.

The proportion of the study population endorsing the "Lives with parents" category represents a further limitation. Individuals who live off campus are less likely to complete surveys than those living on campus $(62 \%$ of on-campus, first students were enrolled, compared to $36 \%$ of students living off-campus). ${ }^{24}$ Based on that, our sample size was adequate, but our cell size for those living with parents was smaller. The smaller cell size could have had an impact on our results, and the results we observed might not represent the student body overall. Samples with a larger proportion of students living with their parents may be necessary to generalize these findings to the broader population of students living with their parents.

The outcome measure of these analyses, grams of ethanol consumed per month, was calculated from 2 ordinal measures of quantity and frequency. Subsequently, the combination of these measures lacks some degree of precision. As with any self-report survey data, subjective bias may also influence responses. The information gathered in this study did not take into consideration individuals who identified as non-binary in regards to gender. This did limit the results of the study to those who identified as male or female. To address this in future studies, questionnaires should provide more identifying options to students. Lastly, measurements were drawn from a single year of data collection; subsequently, the results of these analyses should be interpreted as correlational in nature.

\section{Future Directions}

The relationship between residence status and alcohol consumption is partially accounted for by indirect effects through access to alcohol and perceptions of peer drinking. A remaining direct effect between living with parents and alcohol consumption suggests the existence of other mediating variables not accounted for in these analyses. Future analyses might use a broader range of measures to explain a larger proportion of the relationship in question. Additionally, identifying college samples from universities with a higher proportion of individuals who live at home, or utilization of sampling strategies aimed at recruiting more of these potential subjects may be beneficial in future projects. With a large sample of college students living at home, future investigations may explore heterogeneity within this population; differences in subjects' motivations for living at home may be important determinants of alcohol use in college.

\section{ACKNOWLEDGEMENTS}

The authors thank Dr. Jessica Salvatore for critical suggestions and edits to the text of this manuscript, as well as Dr. Danielle Dick and Dr. Kenneth Kendler for supporting the Spit for Science project.

Spit for Science: The VCU Student Survey has been supported by Virginia Commonwealth University, P20 AA017828, R37AA011408, K02AA018755, and P50 AA022537 from the National Institute on Alcohol Abuse and Alcoholism, and UL1RR031990 from the National Center for Research Resources and National Institutes of Health Roadmap for Medical Research. We would like to thank the VCU students for making this study a success, as well as the many VCU faculty, students, and staff who contributed to the design and implementation of the project. 


\section{REFERENCES}

1. Centers for Disease Control and Prevention, Binge Drinking: Nationwide Problems, Local Solutions, (2013), https:/ / www.cdc.gov/ vitalsigns/BingeDrinking/ index.html (accessed Nov 2016)

2. O’Malley, P. M., Johnston, L. D. (2002) Epidemiology of Alcohol and Other Drug Use among American College Students. J Stud Alcohol 14, 23-39. DOI: http:/ / dx.doi.org/10.15288/jsas.2002.s14.23

3. White, A., Hingson, R. (2014) The Burden of Alcohol Use: Excessive Alcohol Consumption and Related Consequences Among College Students. Alcohol Res 35(2), 201-218.

4. Slutske, W. S. (2005) Alcohol Use Disorders Among US College Students and Their Non-College-Attending Peers. Arch Gen Psychiatry 62(3), 321-327. DOI: https:/ / doi.org/10.1016/s0084-3717(08)70186-7

5. Musgrave-Marquart, D., Bromley, S. P., Dalley, M. B. (1997) Personality, academic attribution, and substance use as predictors of academic achievement in college students. J Soc Behav Pers 12(2), 501-511.

6. Williams, J., Powell, L. M., Wechsler, H. (2003) Does alcohol consumption reduce human capital accumulation? Evidence from the College Alcohol Study. Appl. Econ. 35(10), 1227-1239. DOI: https:// doi.org/10.1080/0003684032000090735

7. Arria, A. M., Caldeira, K. M., Vincent, K. B., Winick, E. R., Baron, R. A., O’Grady, K. E. (2013) Discontinuous college enrolment: associations with substance use and mental health. Psych Serv 64(2) 165-172. DOI: bttps:// doi.org/10.1176/appi.ps.201200106

8. Zeigler, D. W., Wang, C. C., Yoast, R. A., Dickinson, B. D., McCaffree, M. A., Robinowitz, C. B., Sterling, M. L. (2005) The neurocognitive effects of alcohol on adolescents and college students. Prev. Med. 40(1), 23-32. DOI: https://doi.org/10.1016/j.ypmed.2004.04.044

9. Schulenberg, J. E., Sameroff, A. J., Cicchetti, D. (2002) The transition to adulthood as a critical juncture in the course of psychopathology. Dev. Psychopathol 1(4), 799-806. DOI: https://doi.org/10.1017/s0954579404040015

10. Sussman, S., Arnett, J.J. (2014) Emerging adulthood: developmental period facilitative of addictions. Eval. Health Prof $37(2)$, 147-155. DOI: https://doi.org/10.1177/2167696815587422

11. Schulenberg, J.E., Maggs, J.L. (2002) A developmental perspective on alcohol use and heavy drinking during adolescence and the transition to young adulthood. Journal of Studies on Alcohol and Drugs (14), 54-70. DOI: https://doi.org/10.15288/jsas.2002.s14.54

12. Cooke, M.E., Neale, Z.E., Barr, P.B., Myers, J., Dick, D.M., Kendler, K.S., Edwards, A.C. (2016). The role of social, familial, and individual-level factors on stages of alcohol use during the first year of university (Unpublished) Virginia Commonwealth University, Richmond, VA.

13. Wechsler, H., Lee, J.E., Nelson, T.F., \& Kuo, M. (2002) Underage College Students' Drinking Behavior, Access to Alcohol, and the Influence of Deterrence Policies. J Am Coll Health 50(5), 223. DOI: https://doi.org/10.1080/07448480209595714

14. Merrill, J.E., Cary, K.B. (2016) Drinking over the lifespan: focus on college ages. Alcohol Res, 38(1), $103-114$.

15. Baer, John S., Stacy, A., Larimer, M. (1991) Biases in the perception of drinking norms among college students. J Stud Alcohol 52(6), 580-586. DOI: https://doi.org/10.15288/jsa.1991.52.580

16. Ross, L., Green, D. and House, P. (1977) The "False Consensus Effect": An Egocentric Bias in Social Perception and Attribution Processes. J. Exp. Soc. Psychol 13, 279-301. DOI: https:// doi.org/10.1016/0022-1031(77)90049-x

17. Mounts, N. S. (2002). Parental management of adolescent peer relationships in context: The role of parenting style. Journal of Family Psychology, 16(1), 58-69. http://dx.doi.org/10.1037/0893-3200.16.1.58

18. Rulison, K.L., Wahesh, E., Wyrick, D.L., DeJong, W. (2016) Parental influence on drinking behaviors and the transition to college: the mediating role of perceived friend's approval of high risk drinking. J. Stud. Alcohol Drugs 77(4), 638-648. DOI: bttps:/ / doi.org/10.15288/jsad.2016.77.638

19. Harford, T.C., Wechsler, H., Seibring, M. (2002) Attendance and alcohol use at parties and bars in college: a national survey of current drinkers. J Stud Alcohol 63(6), 726-733. DOI: https:// doi.org/10.15288/jsa.2002.63.726

20. Steinberg, L., Fletcher, A., Darling, N. (1994) Parental involvement and Peer Influences on Adolescent Substance Use. Pediatr. 93(6), 1060-1064. DOI: https://doi.org/10.1017/ cbo9780511527906.016

21. Reifman, A., Barnes, G. M., Dintcheff, B. A., Farrell, M. P., Uhteg, L. (1997) Parental and Peer Influences on the Onset of Heavier Drinking among Adolescents. J Stud Alcohol 59(3), 311-317. DOI: https:// doi.org/10.15288/jsa.1998.59.311

22. Arria, A. M., Kuhn, V., Caldeira, K. M., O’Grady, K. E., Vincent, K. B., Wish, E. D. (2008) High school drinking mediates the relationship between parental involvement and college drinking: A longitudinal analysis. Subst Abuse Treat Prev Policy, 3(6). DOI: https:/ / doi.org/10.1186/1747-597x-3-6

23. Kaynak, O., Meyers, K., Caldeira, K. M., Vincent, K. B., Winters, K. C., Arria, A. M. (2013) Relationships among parental involvement and sensation seeking on the development of substance use disorders among college students. Addict Behav 38(1), 1457-1463. DOI: https:// doi.org/10.1016/j.addbeh.2012.08.003

24. Dick, D. M., Nasim, A., Edwards, A. C., Salvatore, J. E., Cho, S. B., Adkins, A...Kendler, K. S. (2014) Spit for Science: launching a longitudinal study of genetic and environmental influences on substance use and emotional health at a large US university. Front Genet. 5(47), 1-12. DOI: https:// doi.org/10.3389/fgene.2014.00047 
25. Steinberg, L., Lamborn, S.D., Dornbusch, S.M. \& Darling, N. (1992). Impact of Parenting Practices on Adolescent Achievement: Authoritative Parenting, School Involvement, and Encouragement to Succeed. Child Dev. 63, 12661281. DOI: https://doi.org/10.2307/1131532

26. Salvatore, J. E., Thomas, N. S., Cho, S. B., Adkins, A., Kendler, K. S., \& Dick, D. M. (2016) The role of romantic relationship status in pathways of risk for emerging adult alcohol use. Psychol Addict Behav 30(3), 335-344. DOI: https://doi.org/10.1037/adb0000145

27. Dawson, D.A. (2011) U.S. low-risk drinking guidelines: An examination of four alternatives. Alcoholism: Clinical and Experimental Research. 2000a;24:1820-1829. DOI: 10.1111/j.1530-0277.2000.tb01986.x

28. Wechsler, H., Nelson, T. F. (2008) What We Have Learned From the Harvard School of Public Health College Alcohol Study: Focusing Attention on College Student Alcohol Consumption and the Environmental Conditions That Promote It. J. Stud. Alcohol Drugs 69, 481-490. DOI: https:/ / doi.org/ 10.15288/jsad.2008.69.481

29. Scribner, R. A., Theall, K. P., Mason, K., Simonsen, N., Schneider, S. K., Towvim, L. G.... DeJong, W. (2011) Alcohol Prevention on College Campuses: The Moderating Effect of the Alcohol Environment on the Effectiveness of Social Norms Marketing Campaigns. Journal of Studies on Alcohol and Drugs, 72(2), 232-239. DOI: https://doi.org/10.15288/jsad.2011.72.232

30. Fachin, A., Aliane, P.P, Martinez, E.Z., Furtado, E.F. (2012) Efficacy of brief alcohol screening intervention for college students (BASICS): a meta-analysis of randomized controlled trials. Substance Abuse Treatment, Prevention, and Policy, 7:40 https://doi.org/10.1186/1747-597X-7-40

31. Hermida, R. (2015) The problem of allowing correlated errors in structural equation modeling: concerns and considerations. CMSS 3(1), 5-17.

\section{ABOUT THE STUDENT AUTHOR}

Katrina Williams worked on this project as an intern with the Spit for Science lab at Virginia Commonwealth University during her senior year. She graduated from Virginia Commonwealth University in December of 2016, with a Bachelor of Science degree in Health and Physical Education with a concentration in Exercise Science. She is currently enrolled in Virginia Commonwealth University's Entry-level Occupational Therapy Doctorate (EL-OTD) program, with a goal of working with the pediatric special needs community.

\section{PRESS SUMMARY}

It is easy to assume that the association between residence status and alcohol use is due to the fact that the college student is living with their parents, and the parents, therefore, are having a large impact on how much their child drinks. Recent studies have shown that this may not be the case. This study looked at other reasons why a college student who lives at home may drink less alcohol than those who do not live at home during their college attending years. This study focused on two factors: how much alcohol college students think other college students drink and how easy alcohol was to obtain. Data were drawn from freshmen attending a four-year university in an urban mid-Atlantic region. The data obtained from these surveys was then used to determine how these factors influence the amount of alcohol that college students who live with their parents consume. Lower perceptions of peer drinking and less access to alcohol in students living with their parents were shown to reduce overall alcohol consumption, relative to students living on campus. While other factors may also play a role in explaining reduced alcohol use in students living with their parents, perceptions of peer drinking and access to alcohol appear to be strong contenders to begin to unwind this apparent trend. 